\title{
Modelling arsenic transport in a river basin: a case study in Finland
}

\author{
Ä. Bilaletdin ${ }^{1}$, H. Kaipainen ${ }^{1}$, T. Ruskeeniemi ${ }^{2}$ \& A. Parviainen ${ }^{3}$ \\ ${ }^{1}$ Pirkanmaa Regional Environment Centre, Finland \\ ${ }^{2}$ Geological Survey of Finland \\ ${ }^{3}$ Helsinki University of Technology, Finland
}

\begin{abstract}
Arsenic undergoes a number of changes in response to environmental conditions such as $\mathrm{pH}$, redox potential and other soluble compounds and solid phases present in the system. As exact transfer modelling requires huge amounts of data, a relatively simple calculation method is needed for large sites. A model has to contain enough essential processes, state variables etc. but it should not require too much data, and the running of the model should not be too laborious. This is especially important for modelling tools designed to assist authorities in their tentative environmental reviews.

The aim of this study is to develop a statistical arsenic transport model for surface waters using monitored data and to take into account the discharge of small rivers and the sub-catchments, calculated using a runoff model. Dilution, sedimentation and chemical processes are presumable processes regarding arsenic transport. The general form of the model is an advection-dispersion model and the first order kinetics. The advection-dispersion model, separately for particle bounded arsenic and soluble arsenic, has been used to simulate the total arsenic concentration. The driving process for particle bounded arsenic is sedimentation and the driving state variable for soluble arsenic is $\mathrm{pH}$. The main conclusion of this study is that by using a quite simple mass balance model it was possible to simulate arsenic transport in surface waters for risk assessment purposes.
\end{abstract}

Keywords: arsenic, transport model, RAMAS, surface water, advectiondispersion. 


\section{Introduction}

RAMAS is a three-year project (2004 - 2007) funded by the participating organizations and the LIFE Environment programme of the European Union. The acronym RAMAS arises from the project title "Risk Assessment and risk Management procedure for ArSenic in the Tampere region". The project is targeting the Province of Pirkanmaa which comprises 28 municipalities, and has 469000 inhabitants within its area.

All over the world, numerous active or abandoned mine sites and ore processing plants bear potential to contaminate their surrounding soils and waters with metals and other compounds. One of the most harmful and rather common elements is arsenic. Because arsenic in ground water and surface water poses a risk to ecosystem and human health, more detailed information is needed on the factors that govern arsenic fate and transport in the environment.

Arsenic undergoes a number of changes in response to environmental conditions such as $\mathrm{pH}$, and redox potential and other soluble compounds and solid phases present in the system. These factors are important as they determine the fate and biological availability of the arsenic in mine tailings, effluent discharge and affected sediments. Several transport models have been proposed for the geochemical cycling of arsenic. Exact modelling requires huge amounts of data and detailed understanding of the whole system. Since this is rarely the case, relatively simple, but sufficiently sensitive calculation method is needed for large sites. A model has to contain the most essential processes, state variables etc. but it should not require too much input data and the running of the model should not be too laborious. The objective of the work presented in this paper is to develop such a transport model.

All over the world a lot of different methods to purify drinking water from arsenic have been studied, as well as, technologies removing arsenic from contaminated soils and waters (e.g. Garelick et al. [1] and Thirunavukkarasu et al. [2]). These studies provide useful information on the behaviour of arsenic in process level. Much less studies have been carried out on arsenic transport in large river basins, even though this is a severe problem in many natural and anthropogenic areas (e.g. Bright et al. [3], Hancock et al. [4], Pettine et al. [5]).

\section{Study area}

The study area in the Vahantajoki river basin comprises an approximately seven kilometres long watercourse, here referred to as the transport route of arsenic, originating from the Ylöjärvi mining area and ending in the Lake Näsijärvi. The transport route begins from the Lake Parosjärvi, which is located in the immediate vicinity of the former mine and the tailings area. The lake is connected to the Stream Parosjärven oja, which flows into the Lake VähäVahantajärvi and into the Stream Vähä-Vahantajärven oja and, finally, into the Lake Näsijärvi, which is the major lake basin in the region. The sub-catchments of the Vahantajoki river basin are specified using a Digital Elevation Map. 
The principal origin of the arsenic contamination in the surface waters of the study area is the copper-tungsten-arsenic (Cu-W-As) mine of Ylöjärvi, which was active during 1943-1966. The mining activities left behind two tailings areas of 4 ha and 17 ha, two open pits and underground galleries. It is estimated that about $4 \mathrm{Mt}$ of tailings and waste rock is stored in the area. After closing the mine, the lake filled up again with water, and as a consequence part of the smaller tailings area, the open pits and the underground galleries filled with tailings were flooded, leaving a lot of arsenic, heavy metals and sulphides containing material subject to leaching of surface and groundwater. Reductive conditions are prevailing at the bottom of the lake, but two times a year seasonal temperature changes of the water mix the oxidative surface water with the deeper one, causing degradation and dissolution of the material. However, the main arsenic sources into the surface waters are the arsenic bearing sulphide minerals in the tailings areas. These minerals tend to weather and dissolve in contact with air and oxidizing rain water releasing arsenic and heavy metals into the environment.

\section{Arsenic in the surface waters}

The Ylöjärvi mine area provides a good reference area for developing a transport model of arsenic. The source term (the tailings area) is relatively well defined, there is long-term data on arsenic and heavy metal concentrations along the whole length of the transport route, as well as, studied information about the environmental impacts, which give some support for process level assumptions. To investigate the short-term dynamic changes in the arsenic transport a monthly monitoring of the surface waters and sediments of streams and lakes were implemented during the RAMAS Project in 2005. The conducted studies depict the gravity of the environmental impacts of the Ylöjärvi mine giving credible background information for further research and transport modelling of arsenic. Table 1 gives the arsenic concentrations in surface waters along the transport route.

Table 1: $\quad$ Arsenic $(\mu \mathrm{g} / \mathrm{l})$ at the various monitoring points of the Vahantajoki river basin. Data from the obligatory sampling under the supervision of the Pirkanmaa Regional Environment Centre reported by Carlson et al. [6] and Parviainen et al. [7].

\begin{tabular}{|c|l|c|c|c|c|c|c|}
\hline & Water sampling point & Year & Mean & Min & Max & Med & N \\
\hline & Ditch from tailings to the Lake Parosjärvi & $1982-1999$ & 258.8 & 43 & 580 & 250 & 25 \\
\hline 1 & Lake Parosjärvi surface & $1975-2005$ & 66.6 & 0.5 & 160 & 68 & 58 \\
\hline & Lake Parosjärvi bottom & $1975-2005$ & 155.3 & 1.2 & 910 & 130 & 56 \\
\hline 2 & Stream Parosjärven oja 1 & $1975-2005$ & 60.2 & 1 & 380 & 60 & 68 \\
\hline 3 & Stream Parosjärven oja 2 & $1975-2005$ & 57.9 & 0.5 & 850 & 31 & 73 \\
\hline 4 & Stream Vähä-Vahantajärven oja & $1975-2005$ & 16 & 0.8 & 65 & 14 & 73 \\
\hline 5 & Stream Vahantajoki alav mts & 2005 & 7.1 & 4 & 14 & 6.3 & 9 \\
\hline 6 & Lake Näsijärvi surface & 2005 & 2.9 & 1.5 & 6 & 3 & 8 \\
\hline & Lake Näsijärvi bottom & 2005 & 23.4 & 6 & 66 & 14 & 8 \\
\hline
\end{tabular}




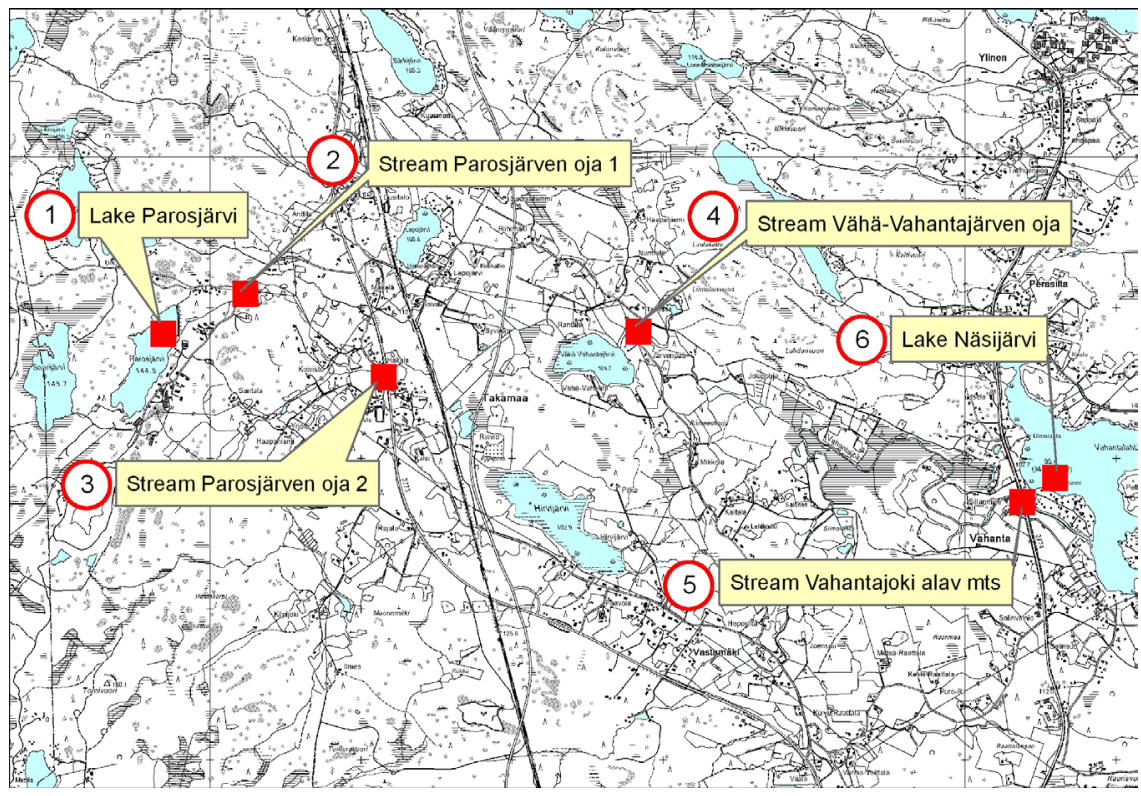

Figure 1: RAMAS project surface water monitoring sites March - December 2005.

Monthly water samples collected by RAMAS imported new information about the dynamic changes in the arsenic transport complementing the annual, long-term monitoring data. In addition to arsenic, many other elements were analyzed from these water samples. These water samples used for the actual transport modelling of arsenic were collected from March to December in 2005 from the Lake Parosjärvi (sampling point 1), the Stream Parosjärven oja (sampling points 2 and 3), Stream Vähä-Vahantajärven oja (4), Stream Vahantajoki (sampling point 5) and Lake Näsijärvi (6) (fig. 1). Two sets of water samples were collected from each sampling point, filtered $(0.45 \mu \mathrm{m})$ and nonfiltered. The filtered $60 \mathrm{ml}$ samples were acidified with $0.3 \mathrm{ml}$ of suprapure nitric acid. The non-filtered samples were used to assess the role of suspended material in the transport. The laboratory analyses were performed with graphite furnace atomic absorption spectrometry (AAG).

The total arsenic values in this data progressively decreased from the Lake Parosjärvi towards the Lake Näsijärvi. The average concentrations of total arsenic in the sampling points were $109 \mu \mathrm{g} / 1$ in the sampling point 1 (surface), $118 \mu \mathrm{g} / 1$ in the sampling point $2,60 \mu \mathrm{g} / \mathrm{l}$ in the sampling point $3,19 \mu \mathrm{g} / 1$ in the sampling point $4,7.2 \mu \mathrm{g} / 1$ in the sampling point 5 and $2,9 \mu \mathrm{g} / 1$ in the sampling point 6 (surface).

\section{Model development}

The aim of the arsenic transport model was to develop an empirical model using monitored data and to take into account the discharge of small rivers and the sub- 
catchments of the Vahantajoki river basin. The results of the sampling performed in 2005 were used in the study due to the limitations in the old data, which provided the total arsenic concentrations instead of the separation of dissolved and particulate-bounded fractions.

The dynamical discharge values of small rivers in the study area can be calculated using the runoff model, VESISTÖMALLI, developed at the Finnish Environment Institute by Vehviläinen [8]. This model takes into account the meteorological and hydrological variables in the area. The model is based on a conceptual distributed runoff model, which is a Finnish version of the original HBV runoff model by Bergström [9], and water balance model for lake, river routing model and flood area models.

Although quite rarely applied to metals, the mass-balance approach offers a useful technique for quantifying the transport of trace elements such as arsenic in surface water. In mass-balance considerations data on both hydrological conditions and chemical quality of water are taken into account simultaneously. Dilution, sedimentation and chemical processes are presumable processes controlling arsenic transport. The general form of the model is an advectiondispersion model and first order kinetics using eqn (1). The traditional advectiondispersion equation is a standard model for contaminant transport presented e.g. Kinnunen et al. [10]. In the model the river basin is divided into hydraulic elements parallel to the surface of the river basin. Hydraulic elements are considered to be homogenous and therefore differences in water quality are observed along the vertical axis of the river basin. The two basic principles of the model are the conservation of mass and the kinetic principle. The first principle implies conservation of mass even though material is changed in chemical and biological reactions from one form to another, while the kinetic principle states that the rate of change of a concentration is equal to the product of a coefficient and the concentrations of one or more variables that interact to cause the change. Estimation of parameters can be accomplished on the basis of experiments carried out in the field or in the laboratory, or parameters may be taken from the literature or estimated by calibration.

$$
A_{x} \frac{\partial c}{\partial t}=\frac{\partial}{\partial x}\left(A_{x} D_{L} \frac{\mathrm{a}}{\partial x}\right)-\frac{\partial}{\partial x}\left(A_{x} u c\right)+S(c, F e, p H \ldots) A_{x}
$$

$$
\begin{array}{ll}
\mathrm{c} & =\text { concentration of arsenic } \\
\mathrm{t} & =\text { time } \\
\mathrm{x} & =\text { distance } \\
\mathrm{A}_{\mathrm{x}} & =\text { area of the element } \\
\mathrm{D}_{\mathrm{L}} & =\text { dispersion coefficient } \\
\mathrm{u} & =\text { advective velocity } \\
\mathrm{S} & =\text { transformation processes }
\end{array}
$$

The first term on the right-hand side describes diffusion and the second one vertical advection. The third term describes transformation processes, e.g. chemical transformation and settling phenomena. In this application diffusion is a minor factor. 
The starting point in developing the arsenic loss model was to assume that the transformation process obeys first order kinetics with a constant reaction rate coefficient. It means that all transformation processes can be defined by one constant reaction rate coefficient (eqn 2), since almost all transformation processes in the nature can be simplified.

$$
S=-\rho c
$$

$\rho=$ reaction rate coefficient of transformation processes

In fig. 2, the advection-dispersion model (eqn 1 and eqn 2) has been used to simulate the total arsenic concentration in different sampling points in 2005.

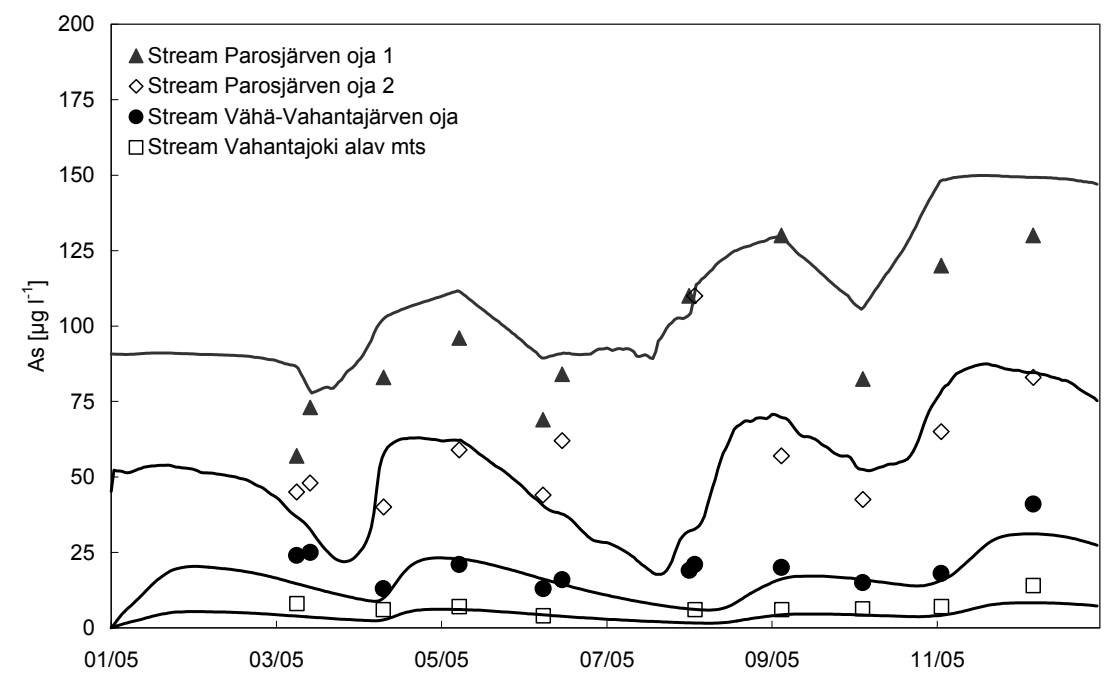

Figure 2: The simulation results of total arsenic concentration in different surface water sampling points from 2005 in the Ylöjärvi mine area using an advection-dispersion model and first order kinetics.

We can see that the results of the simulation are generally moderate in different sampling points but particularly in the beginning of the transport route (sampling point 2, Stream Parosjärven oja 1) a difference between the observations and the simulated results is quite significant. Therefore a more sophisticated description of transformation processes was tested.

It seemed reasonable to divide total arsenic to particle-bounded and dissolved arsenic and to consider the different processes affecting the transport of arsenic, eqn 3 .

$$
c=c_{p}+c_{s}
$$


$c_{p}=$ concentration of particle bounded arsenic

$\mathrm{c}_{\mathrm{s}}=$ concentration of soluble bounded arsenic

Particle bounded and soluble arsenic are behaving independently and these fractions have their own characteristic reaction processes. Generally we can write the following eqns (4-6):

$$
\begin{gathered}
S=S_{p}+S_{s} \\
S_{p}=-\rho_{p} c_{p} \\
S_{S}=-\rho_{s} c_{s}
\end{gathered}
$$

$\rho_{\mathrm{p}}=$ particle bounded arsenic process coefficient $\rho_{\mathrm{s}}=$ soluble arsenic process coefficient

There was no universal equation available and, therefore, for particle bounded arsenic sedimentation process was chosen as a principle factor controlling the arsenic transport in solid phase (eqn (5)). It is known that soluble arsenic reacts chemically in many ways. Complex ions of arsenic interact with secondary iron oxides and hydroxides, and in varying degrees with many manganese and aluminium precipitates. Clay and humus are also known to be good absorbents of arsenic. In this study the different correlations between soluble arsenic and other state variables were checked, but only the correlation of $\mathrm{pH}$ turned out to be significant (figs. 3 and 4). Therefore the equations (7) and (8) are the following:

$$
\begin{gathered}
\rho_{s}=f(p H) \rho^{\prime} \\
f(p H)=-1.5 p H+12
\end{gathered}
$$

In fig. 5 the advection-dispersion model has been exploited separately for particle-bounded arsenic and soluble arsenic to simulate the total arsenic concentration in different sampling points. The driving process for particlebounded arsenic is sedimentation and the driving state variable for soluble arsenic is $\mathrm{pH}$. When comparing figs. 2 and 5 it is evident the simulation result did not get essentially better, which suggests that the system is more complex and probably several factors not considered in this exercise are affecting the behaviour of arsenic. However, the model is capable to produce a fairly good estimate of the fate of arsenic in the transport route and the present version provides a sound basis for further developing work.

The final simulation equations in this study were eqns (9) and (10) for particle bounded and soluble arsenic, respectively. 


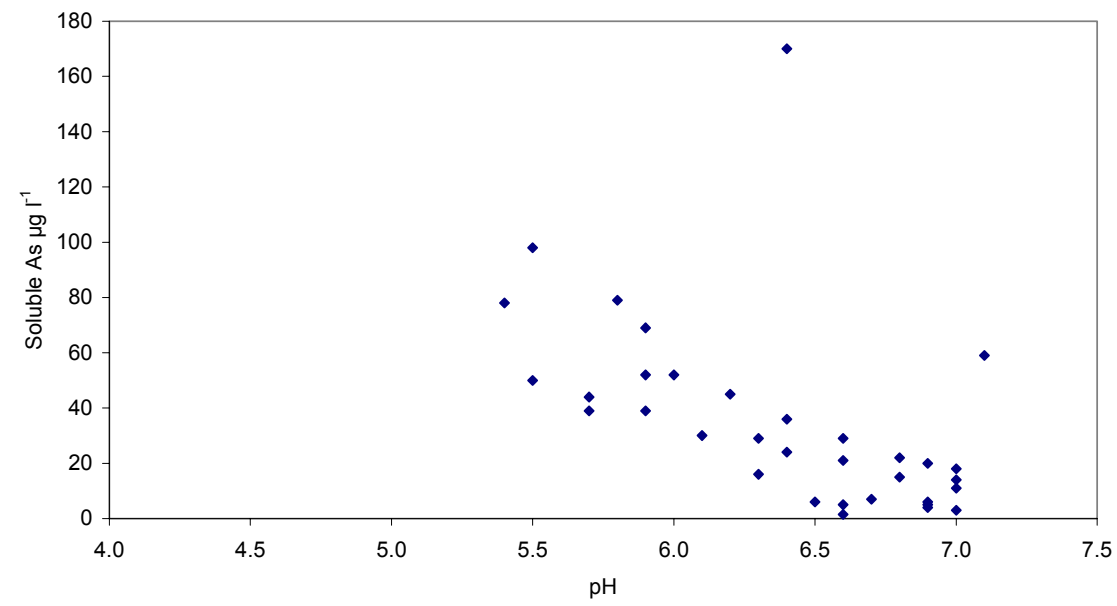

Figure 3: A correlation between $\mathrm{pH}$ and soluble arsenic in the Vahantajoki river basin in 2005 .

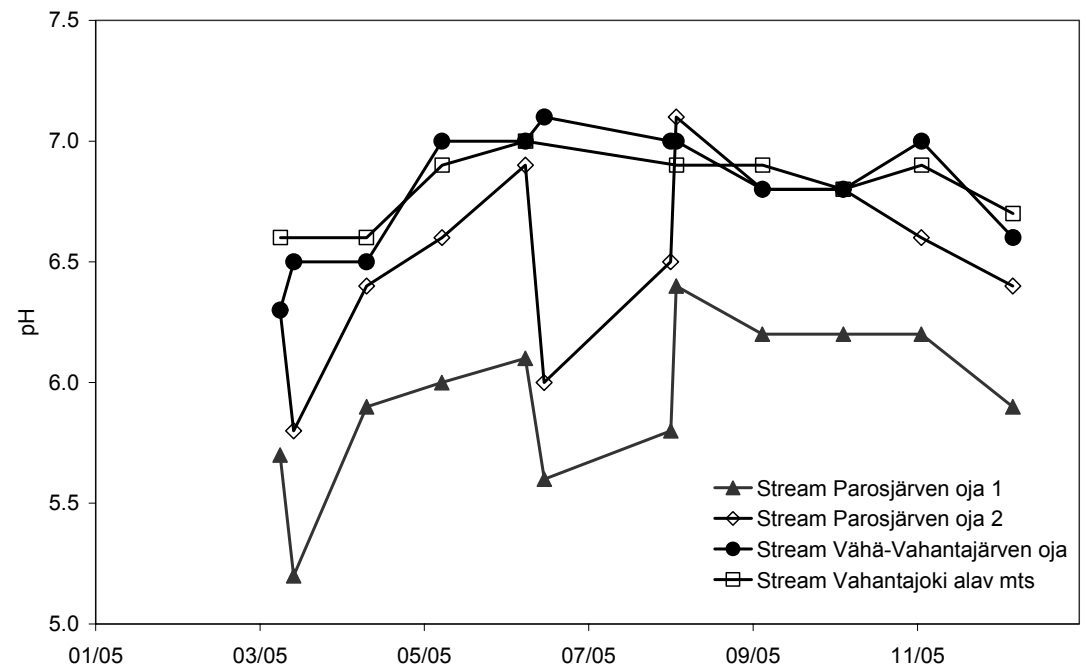

Figure 4: The $\mathrm{pH}$ values in different surface water sampling points in the Vahantajoki river basin in 2005. The $\mathrm{pH}$ increases down stream and the variations become less drastic and abrupt.

$$
\begin{gathered}
A_{x} \frac{\partial c_{p}}{\partial t}=\frac{\partial}{\partial x}\left(A_{x} D_{L} \frac{\partial c_{p}}{\partial x}\right)-\frac{\partial}{\partial x}\left(A_{x} u c_{p}\right)-\rho_{p} c_{p} \\
A_{x} \frac{\partial c_{s}}{\partial t}=\frac{\partial}{\partial x}\left(A_{x} D_{L} \frac{\partial c_{s}}{\partial x}\right)-\frac{\partial}{\partial x}\left(A_{x} u c_{s}\right)-(1.5 p H+12) \rho_{s}^{\prime} c_{s}
\end{gathered}
$$




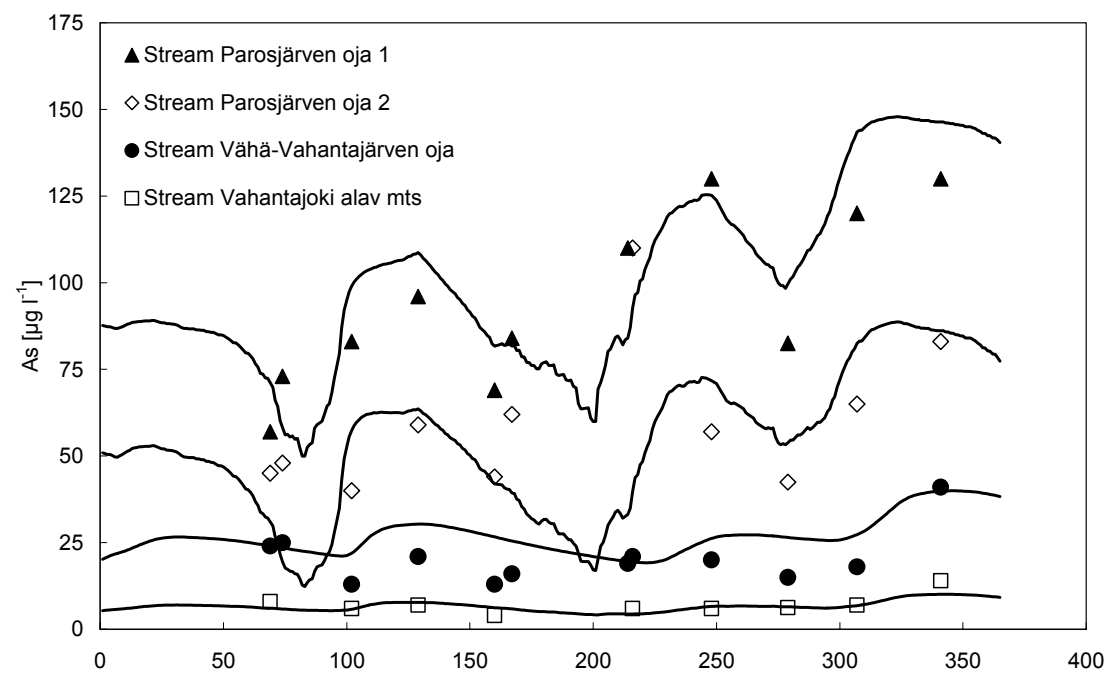

Figure 5: The advection-dispersion model, separately for particle bounded arsenic and soluble arsenic, has been used to simulate the total arsenic concentration in different sampling points in 2005.

\section{Summary}

The main result of this model development is that by using a quite simple mass balance model it was possible to simulate arsenic transport in different circumstances. Dilution, sedimentation and chemical processes are presumable processes regarding arsenic transport. One main goal of this approach was that on a catchment scale a relevant data survey should not be too laborious and expensive. The general form of the model is an advection-dispersion model and the first order kinetics. In order to improve the model and to understand the processes of a transport phenomenon, the particle bounded and dissolved fractions were treated separately. A fit of the simulation was better than using only total arsenic. The applied driving process for particle-bounded arsenic is sedimentation and the driving state variable for soluble arsenic is $\mathrm{pH}$. Using this kind of approach the basic features of arsenic transportation can be studied and relevant data for risk assessment purposes can be produced. An advantage of this model is that it does not need very sophisticated data to achieve estimates of arsenic transport for surface waters in large catchments. The present model version provides a good starting point for future development.

\section{References}

[1] Garelick, H., Dybowska, A., Valsami-Jones, E. \& Priest, N., Remediation Technologies for Arsenic Contaminated Drinking Waters. Journal of Soils and Sediment, 5(3), pp. 182-190, 2005. 
[2] Thirunavukkarasu, O.S., Viraraghavan, T. \& Subramanian, K.S., Arsenic removal from drinking water using granular ferric hydroxide. Water $S A$, 29, pp. 161-170, 2003.

[3] Bright, D.A., Coedy, B., Dushenko, W.T. \& Reimer, K.J., Arsenic transport in a watershed receiving gold mine effluent near Yellowknife, Canada. Total. Environ., 155, pp. 237-252, 1994.

[4] Hancock, T.C., Denver, J.M., Riedel, G.F. \& Miller, C.V., Source, transport, and fate of arsenic in the Pocomoke River basin, a poultry dominated Chesapeake Bay watershed. U.S. Geol. Survey Workshop Arsenic in the environment, Denver, CO, 2001

[5] Pettine, M., Camusso, M. \& Martinotti, W., Dissolved and particulate transport of arsenic and chromium in the Po River, Italy. Sci. Tot. Environm., 119, pp. 253-280, 1992.

[6] Carlson, L., Hänninen, P. \& Vanhala, H., Ylöjärven Paroistenjärven kaivosalueen nykytilan selvitys. Geological Survey of Finland, Report S/41/0000/3/2002, 2002.

[7] Parviainen, A., Vaajasaari, K., Loukola-Ruskeeniemi, K., Kauppila, T., Bilaletdin, Ä., Kaipainen, H., Tammenmaa, J. \& Hokkanen, T., Anthropogenic Arsenic Sources in the Tampere Region in Finland. Miscellaneous Publications of Geological Survey of Finland, Espoo, 2006

[8] Vehviläinen, B., The watershed simulation and forecasting system in the National Board of Waters and Environment. Publications of the Water and Environment Research Institute. Helsinki, National Board of Waters and Environment, 17, 1994.

[9] Bergström, S., Development and application of a conceptual runoff model for Scandinavian catchments. SMHI reporter, RHO 7, Norrköping, 1976.

[10] Kinnunen, K., Nyholm, B., Niemi, J., Frisk, T., Kyläharakka, T. \& Kauranne, T., Water quality modelling of Finnish water bodies. Publications of the Water Research Institute, 46, Helsinki, National Board of Waters and Environment, 1982. 